\title{
Knowledge regarding factors that influence fertility in Thai reproductive-age population living in urban area: A cross-sectional study
}

\author{
Sarapan Na Nakhon, Pawan Limvorapitux, Patsama Vichinsartvichai \\ Infertility Unit, Department of Obstetrics and Gynecology, Faculty of Medicine Vajira Hospital, Navamindradhiraj University, Bangkok, Thailand
}

Objective: To survey knowledge about the factors that influence fertility in a reproductive-age population living in an urban area.

Methods: A cross-sectional study was conducted using a questionnaire-based survey among both males and females aged 18-45 years living in the Bangkok metropolitan area.

Results: The mean age of the participants was $26.8 \pm 7.2$ years (male, $41.9 \%$; female, $58.1 \%$ ). Of the participants, $53.1 \%$ had an undergraduate degree and $57.1 \%$ were single. Only one-fifth of the participants correctly identified the age when fecundity declines in male and female, the definition of infertility, and the period during the menstrual cycle with the highest chance of pregnancy. Approximately three-fourths of the participants correctly identified that cigarette smoking, alcohol consumption, and sexually transmitted infections affect fertility.

Conclusion: A considerable knowledge gap about the factors that influence fertility was identified in reproductive-age individuals in an urban area of Thailand. This issue should be urgently addressed by promoting fertility awareness through education, discussions about social perceptions regarding fertility, and reliable sources of knowledge.

Keywords: Age factors; Fertility; Infertility; Reproduction

\section{Introduction}

The global fertility rate has drastically decreased over the last decade. This trend has also been observed in Thailand. The total fertility rate in Thailand decreased by approximately two-thirds over last three decades [1]. More couples have chosen to delay childbearing, making natural conception more difficult, and assisted reproductive technology is more often needed to achieve pregnancy [2].

Several factors affect reproductive health and fertility [3]. Age is the most important factor in both male and female. Starting at the age

Received: Oct 10, 2017 · Revised: Dec 12, 2017 · Accepted: Feb 8, 2018 Corresponding author: Pawan Limvorapitux

Infertility Unit, Department of Obstetrics and Gynecology, Faculty of Medicine Vajira Hospital, Navamindradhiraj University, 681 Samsen Rd., Dusit, Bangkok 10300, Thailand

Tel: +66-2244-3405 Fax: +66-2243-7907 E-mail: pawan.limx@gmail.com

This is an Open Access article distributed under the terms of the Creative Commons Attribution Non-Commercial License (http://creativecommons.org/licenses/by-nc/4.0/) which permits unrestricted non-commercial use, distribution, and reproduction in any medium, provided the original work is properly cited. of 30 years, women's fecundity gradually declines. Fecundity steeply declines after the age of 35 years $[4,5]$. Delayed childbearing is associated with increased rates of aneuploidy and spontaneous abortion [6]. In males, the age threshold of decreased fecundity seems to be a bit later. Sperm concentration, motility, and morphology have been found to decline after 40 years [7], concomitantly with increased levels of reactive oxygen species (ROS) in semen and DNA fragmentation $[8,9]$. Other fertility-related pathologies, such as varicocele, genital inflammation, and other systemic diseases, are found more often with advancing age $[4,10]$.

Strong evidence exists regarding the effects of cigarette smoking, alcohol consumption, sexually transmitted infections (STIs), and obesity on fertility [3]. Cigarette smoking stimulates the depletion of ovarian follicles and shortens the reproductive lifespan. Maternal smoking is also associated with spontaneous miscarriage, intrauterine growth restriction, preterm labor, and placental abruption [11]. Paternal smoking increases sperm DNA fragmentation and impairs sperm quality $[12,13]$. Alcohol consumption enhances the produc- 
tion of ROS, which worsen the quality of the oocyte and spermatozoa, contributing to infertility [14]. Various mechanisms contribute to the unfavorable effects of obesity on fertility. Obese male produce less testosterone and more inflammatory cytokines, resulting in a higher production of ROS [15]. Obesity affects fertility in female by causing hormonal disturbances and anovulation. Obese female have lower levels of sex hormone binding globulin and higher levels of free androgen [3]. Female with a higher body mass index have more adverse pregnancy outcomes, such as fetal death, gestational diabetes mellitus, and hypertension [16-18]. Lastly, STIs have an adverse effect on fertility. Chlamydia trachomatis and Neisseria gonorrhoeae can cause urethral stricture and epididymo-orchitis in male and lead to male infertility [19]. Chlamydia infection in female causes pelvic inflammatory disease, which eventually leads to tubal factor infertility [20]. The incidence of infertility was also found to be increased by exposure to psychological stress, environmental pollutants, and gonadotoxic treatments [3].

Most people lack knowledge about the age-related decline in fertility and have an insufficient awareness of the modifiable and nonmodifiable factors related to fertility [10,21-23]. Numerous misconceptions exist regarding the most fertile time during the menstrual cycle and when to seek treatment after conception does not take place. The aim of this study was to assess knowledge regarding the factors that influence fertility in a reproductive-age population living in an urban area of Thailand.

\section{Methods}

\section{Study design and participants}

A cross-sectional study was done using a non-random sampling technique from January to April 2017. The study was conducted in accordance with the ethical principles of the Declaration of Helsinki, and the Institutional Review Board of Vajira Hospital approved the study protocol.

We recruited both males and females aged between 18 and 45 years who had lived in Bangkok metropolitan area for at least 3 months with sufficient Thai language proficiency to participate in a questionnaire survey. An adequate sample size was calculated to be 380 participants, using $95 \%$ confidence intervals.

\section{Outcome measures}

A questionnaire was developed by reviewing the factors influencing fertility and related information published in previous studies $[21,23,24]$. The questionnaire was validated by three reproductive medicine specialists, with an index of Item-Objective Congruence score of 0.5 . In a pilot study of 20 participants, the reliability of the questionnaire was 0.702 (Cronbach $\alpha$ ).
The questionnaires consisted of three parts. The first part included socioeconomic and reproductive characteristics such as age, sex, marital status, level of education, income, and childbearing plan. The second part assessed participants' knowledge of factors that influence fertility. Single-best-answer questions were asked about the age when fertility starts to decline in female and in male, the time interval when a couple should be diagnosed with infertility, and the period in the menstrual cycle when pregnancy is most likely to occur. Knowledge about the effects of modifiable factors on fertility (cigarette smoking, alcohol consumption, obesity, STIs) was also surveyed with single-best-answer questions. The final part of the questionnaire asked about respondents' preferred sources of information about reproductive health.

\section{Statistical analysis}

The data were analyzed using IBM SPSS ver. 22.0 (IBM Corp., Armonk, NY, USA). Continuous data were tested for normality using a histogram, a normal Q-Q plot, and the Kolmogorov-Smirnov test. Data are presented as mean and standard deviation, median and minimum-maximum, or number and percentage. Knowledge was compared between the sexes using the chi-square test. The $p$-values $<0.05$ were considered to indicate statistical significance.

\section{Results}

The socioeconomic and reproductive characteristics of 401 participants are summarized in Table 1. The average age of participants was $26.87 \pm 7.22$ years, and $58.1 \%$ were female and $41.9 \%$ were male. The majority of participants (53.1\%) had an undergraduate degree, and $57.1 \%$ of them were single. One-fourth of the participants had at least one child.

The participants' knowledge of factors influencing fertility is shown in Table 2. Only $13 \%$ of participants correctly identified that female fecundity starts to decline at the age of 30-34 years (male, 10\%; female, $15 \% ; p=0.02$ ). Only $18.5 \%$ of the participants correctly identified that male fertility starts to decline at the age of 40-44 years (male, 17\%; female, 19\%; $p=0.364$ ). Most of the participants did not know the correct definition of infertility $(16.1 \%$ of males and $25.8 \%$ of females correctly answered, $p=0.174$ ). Only $22 \%$ of participants recognized the period during the menstrual cycle when conception is most likely (male, $20.2 \%$; female, $23.6 \%$; $p=0.098$ ).

Participants' knowledge of the effects of modifiable factors on fertility is shown in Table 3. Three-fourths of the participants correctly identified that cigarette smoking, alcohol consumption, and STls affect fertility. However, only half of them recognized that obesity affects fertility (male, $45.2 \%$; female, $50.6 \% ; p=0.308$ ). Approximately 93\% of participants recalled having learned about fertility at some 
Table 1. Socioeconomic and reproductive characteristics of the participants stratified by sex

\begin{tabular}{|c|c|c|c|c|}
\hline Characteristics & Male $(n=168)$ & Female $(n=233)$ & All $(n=401)$ & $p$-value $e^{a)}$ \\
\hline Age (yr) & $26.17 \pm 6.82$ & $27.37 \pm 7.47$ & $26.87 \pm 7.22$ & 0.1 \\
\hline Annual income (USD/yr) & & & & 0.585 \\
\hline No income & $44(26.2)$ & $68(29.2)$ & $112(27.9)$ & \\
\hline$<4,000$ & $35(20.8)$ & $46(19.7)$ & $81(20.2)$ & \\
\hline $4,000-19,999$ & $85(50.6)$ & $108(46.4)$ & $193(48.1)$ & \\
\hline $20,000-40,000$ & $4(2.4)$ & $9(3.9)$ & $13(3.2)$ & \\
\hline$>40,000$ & 0 & $2(0.9)$ & $2(0.5)$ & \\
\hline Level of highest education & & & & 0.206 \\
\hline Primary school or less & $12(7.1)$ & $11(4.7)$ & $23(5.7)$ & \\
\hline High school & $50(29.8)$ & $75(32.2)$ & $125(31.2)$ & \\
\hline Certificate and diploma & $10(6.0)$ & $14(6.0)$ & $24(5.9)$ & \\
\hline Undergraduate & $92(54.8)$ & $121(51.9)$ & $213(53.1)$ & \\
\hline Postgraduate & $4(2.4)$ & $12(5.2)$ & $16(4.0)$ & \\
\hline Marital status & & & & 0.198 \\
\hline Single & $99(58.9)$ & $130(55.8)$ & $229(57.1)$ & \\
\hline Married & $65(38.7)$ & $89(38.2)$ & $154(38.4)$ & \\
\hline Separated or divorced & $4(2.4)$ & $14(6.1)$ & $18(4.5)$ & \\
\hline Have children & $32(19.0)$ & $62(26.6)$ & $94(23.4)$ & 0.078 \\
\hline No. of children & $1.56 \pm 0.67$ & $1.95 \pm 0.99$ & $1.82 \pm 0.915$ & 0.05 \\
\hline Childbearing plan & & & & 0.122 \\
\hline No plan & 75 (44.6) & $127(54.5)$ & $202(50.4)$ & \\
\hline Within 5 years & $44(25.0)$ & $58(14.9)$ & $100(25)$ & \\
\hline Over 5 years & $51(30.4)$ & $48(20.6)$ & $99(24.6)$ & \\
\hline
\end{tabular}

Values are presented as mean \pm standard deviation or number (\%).

${ }^{\text {a) }}$ Data were compared between male and female using the independent sample $t$-test or the chi-square test, as appropriate.

point in their lifetime (data not shown). The sources of their existing knowledge were the Internet, TV, or radio (66.3\%), school (63.3\%), and healthcare providers (45.1\%). Participants' preferred resources were the Internet, TV, or radio (66.3\%), healthcare providers (43.4\%), and school (29.2\%).

\section{Discussion}

Most of our participants incorrectly identified the effects of age on fertility. Male participants knew significantly less than their female counterparts about the impact of female's age on fertility, similarly to a previous study [23]. Female perceived their fertility as starting to decline approximately 5 years later than is the case in reality. This misperception was also detected by Madsen [25]. The majority of our participants did not know when male fertility starts to decline. This finding was in contrast to the study conducted by Hammarberg et al. [23], in which most of the participants had correct knowledge on this issue.

Only one-fifth of our participants knew how infertility is diagnosed. Moreover, a large proportion of participants did not recognize ovulation as the point when conception is most likely. A lack of fertility awareness and knowledge of issues related to fertility might contrib- ute to delayed childbearing, infertility, and increased utilization of assisted reproductive technology, decreasing the fertility rate [26].

Various modifiable factors affect fertility, including cigarette smoking, alcohol consumption, obesity, and STIs [12,15,18]. Most of our participants correctly recognized that cigarette smoking, alcohol consumption, and STIs have deleterious effects on fertility. This finding is congruent with data from a previous study [24]. However, only half of our participants recognized that obesity affects fertility. This discrepancy in knowledge between obesity and other modifiable factors among our participants might reflect the more extensive promotion of smoking control, alcohol consumption control and STI/human immunodeficiency virus control by the Thai Health Promotion Foundation among the public [27]. Moreover, cigarette smoking, alcohol consumption, and STIs are stigmatized as being among the seven deadly sins in health [27-30]. Although the impacts of obesity on healthcare and the social and economic sectors of society are similar to those of other modifiable factors, the public perception of obesity as a health threat in Thailand is less widespread [31]. The knowledge of our participants regarding these modifiable factors may mean that they gave correct answers shaped by a general awareness of how these factors influence other issues affecting the public, and may not have corresponded to their true perceptions re- 
Table 2. Knowledge of participants about factors influencing fertility

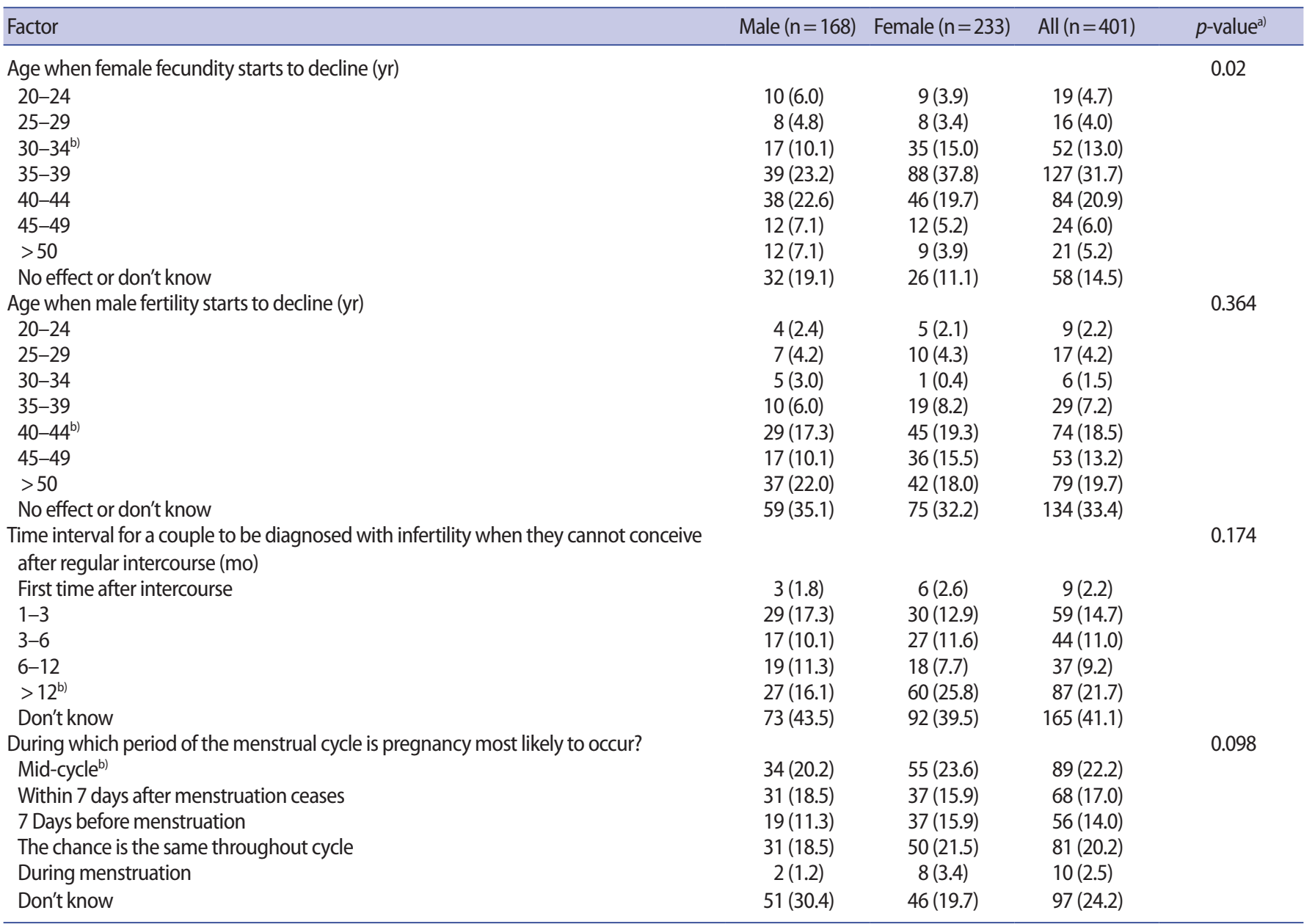

Values are presented as number (\%).

a) The $p$-values reflect comparisons of the proportion of male and female who responded with the correct answer; data were analyzed using the chi-square test; ${ }^{b)}$ Correct answer.

Table 3. Knowledge of whether modifiable factors affect fertility

\begin{tabular}{lccc}
\hline Factor & Male $(n=168)$ & Female $(\mathrm{n}=233)$ & All $(\mathrm{n}=401)$ \\
\hline Cigarette smoking & & & \\
Yes & $119(70.8)$ & $174(74.7)$ & $293(73.1)$ \\
No & $18(10.7)$ & $25(10.7)$ & $43(10.7)$ \\
Unsure & $31(18.7)$ & $34(14.6)$ & $65(16.2)$ \\
Alcohol consumption & & & \\
Yes & $124(73.8)$ & $186(79.8)$ & $310(77.3)$ \\
No & $20(11.9)$ & $29(12.4)$ & $49(12.2)$ \\
Unsure & $24(14.3)$ & $18(7.7)$ & $42(10.5)$ \\
Obesity & & & $194(48.4)$ \\
Yes & $76(45.2)$ & $118(50.6)$ & $130(32.4)$ \\
No & $54(32.1)$ & $39(32.6)$ & $77(19.2)$ \\
Unsure & $38(22.6)$ & $39(16.7)$ & $293(73.1)$ \\
Sexually transmitted infection & & $180(77.3)$ & $53(13.2)$ \\
Yes & $113(67.3)$ & $29(12.4)$ & $55(13.7)$ \\
No & $24(14.3)$ & $24(10.3)$ & 0.308 \\
Unsure & $31(18.5)$ & & 0.043 \\
\hline
\end{tabular}

Values are presented as number (\%).

a)Data were analyzed using the chi-square test. 
garding fertility.

Although $94.2 \%$ of our participants had at least a high school education, the overall knowledge regarding the factors that influence fertility among reproductive-age participants in an urban area of Thailand was still poor. Multiple considerations may explain our findings. First, formal education regarding fertility and related factors does not exist in Thailand's basic education curriculum [32]. The reproductive health topics covered in the curriculum focus on STIs prevention and contraception. Moreover, the Ministry of Education of Thailand seems not to take sex education seriously. The budget is limited and there are few sex educators. Thai health educators only teach sex education for 8-9 hours per academic year [33]. Second, sex is stigmatized as a sinful and dirty act within the complex religious and cultural framework of Buddhism in modern Thailand [34]. Most fertile people seek out information from their peers, who might have an inadequate level of knowledge. Finally, reliable sources of information about fertility and reproductive health in Thailand are very limited. Only a single government-developed website addresses these issues [35], and only a few reliable Internet resources from the private sector are available for the general population.

The major advantages of our study are the interview-based methodology and our community-based sample of participants. We utilized a direct questionnaire survey, which contributed to the achievement of a 100\% response rate. Community-based participants are expected to provide data that are more comparable to the general population than hospital-based surveys. Ali et al. [24] conducted a hospital-based survey of knowledge regarding the factors that influence infertility among the persons accompanying infertility patients. That study may have contained a bias toward better knowledge since the participants were in a close relationship with infertility patients. Hammarberg et al. [23] conducted a survey by landline telephone interviews, but $86.6 \%$ of the telephone calls did not lead to any data being gathered. Their response rate was only $14.4 \%$, reflecting logistical challenges in their research.

Our number of participants may be a limitation even though it is comparable to the samples of other studies [23,24]. In light of the large population (9 million) of Bangkok and the low proportions of correct knowledge that we observed [36], a larger number of participants might be warranted as a way to investigate a more meaningful and representative group. Moreover, selection bias always arises as a potential limitation of non-random study. Future research should investigate a representative, random-based sample of the Thai population with stratification by region to obtain accurate data regarding these issues throughout the whole country.

In summary, most of the reproductive-age participants living in an urban area of Thailand incorrectly identified the factors that influence fertility. Strategies to promote fertility awareness among resi- dents of Bangkok are urgently required to overcome the consequences of delayed childbearing and to increase the total fertility rate. Fertility awareness information platforms should be readily available, and reliable and sustainable Internet-based resources may be the platform of choice.

\section{Conflict of interest}

No potential conflict of interest relevant to this article was reported.

\section{Acknowledgments}

The authors would like to express deep gratitude to Dr. Busaba Supawattanabodee for her valuable advice on study design and questionnaire development.

\section{References}

1. United Nations. World fertility patterns 2015 [Internet]. San Francisco: United Nations; 2015 [cited 2018 Feb 27]. Available from: http://www.un.org/en/development/desa/population/publications/pdf/fertility/world-fertility-patterns-2015.pdf.

2. Harris K, Burley H, McLachlan R, Bowman M, Macaldowie A, Taylor $\mathrm{K}$, et al. Socio-economic disparities in access to assisted reproductive technologies in Australia. Reprod Biomed Online 2016;33:575-84.

3. Petraglia F, Serour Gl, Chapron C. The changing prevalence of infertility. Int J Gynaecol Obstet 2013;123 Suppl 2:S4-8.

4. Utting D, Bewley S. Family planning and age-related reproductive risk. Obstetrician Gynaecologist 2011;13:35-41.

5. Vichinsartvichai P, Siriphadung S, Traipak K, Promrungrueng P, Manolertthewan $C$, Ratchanon $S$. The influence of women age and successfulness of intrauterine insemination (IUI) cycles. J Med Assoc Thai 2015;98:833-8.

6. American College of Obstetricians and Gynecologists Committee on Gynecologic Practice and Practice Committee. Female agerelated fertility decline: committee opinion No. 589. Fertil Steril 2014;101:633-4.

7. Stone BA, Alex A, Werlin LB, Marrs RP. Age thresholds for changes in semen parameters in men. Fertil Steril 2013;100:952-8.

8. Cocuzza M, Athayde KS, Agarwal A, Sharma R, Pagani R, Lucon $A M$, et al. Age-related increase of reactive oxygen species in neat semen in healthy fertile men. Urology 2008;71:490-4.

9. Vagnini L, Baruffi RL, Mauri AL, Petersen CG, Massaro FC, Pontes $A$, et al. The effects of male age on sperm DNA damage in an infertile population. Reprod Biomed Online 2007;15:514-9.

10. Deatsman S, Vasilopoulos T, Rhoton-Vlasak A. Age and fertility: a 
study on patient awareness. JBRA Assist Reprod 2016;20:99-106.

11. Tong VT, Kissin DM, Bernson D, Copeland G, Boulet SL, Zhang Y, et al. Maternal smoking among women with and without use of assisted reproductive technologies. J Womens Health (Larchmt) 2016;25:1066-72.

12. Practice Committee of the American Society for Reproductive Medicine. Smoking and infertility: a committee opinion. Fertil Steril 2012;98:1400-6.

13. Cui X, Jing X, Wu X, Wang Z, Li Q. Potential effect of smoking on semen quality through DNA damage and the downregulation of Chk1 in sperm. Mol Med Rep 2016;14:753-61.

14. Opuwari CS, Henkel RR. An update on oxidative damage to spermatozoa and oocytes. Biomed Res Int 2016;2016:9540142.

15. Kahn BE, Brannigan RE. Obesity and male infertility. Curr Opin Urol 2017;27:441-5.

16. Nohr EA, Bech BH, Davies MJ, Frydenberg M, Henriksen TB, Olsen J. Prepregnancy obesity and fetal death: a study within the Danish National Birth Cohort. Obstet Gynecol 2005;106:250-9.

17. Chu SY, Kim SY, Lau J, Schmid CH, Dietz PM, Callaghan WM, et al. Maternal obesity and risk of stillbirth: a metaanalysis. Am J Obstet Gynecol 2007;197:223-8.

18. Morales-Suarez-Varela M, Nohr EA, Bech BH, Wu C, Olsen J. Smoking, physical exercise, BMI and late foetal death: a study within the Danish National Birth Cohort. Eur J Epidemiol 2016; 31:999-1009.

19. Ochsendorf FR. Sexually transmitted infections: impact on male fertility. Andrologia 2008;40:72-5.

20. Kramer DG, Brown ST. Sexually transmitted diseases and infertility. Int J Gynaecol Obstet 1984;22:19-27.

21. Abolfotouh MA, Alabdrabalnabi AA, Albacker RB, Al-Jughaiman UA, Hassan SN. Knowledge, attitude, and practices of infertility among Saudi couples. Int J Gen Med 2013;6:563-73.

22. Bunting L, Tsibulsky I, Boivin J. Fertility knowledge and beliefs about fertility treatment: findings from the International Fertility Decision-making Study. Hum Reprod 2013;28:385-97.

23. Hammarberg K, Setter T, Norman RJ, Holden CA, Michelmore J, Johnson L. Knowledge about factors that influence fertility among Australians of reproductive age: a population-based survey. Fertil Steril 2013;99:502-7.
24. Ali S, Sophie R, Imam AM, Khan FI, Ali SF, Shaikh A, et al. Knowledge, perceptions and myths regarding infertility among selected adult population in Pakistan: a cross-sectional study. BMC Public Health 2011;11:760.

25. Madsen P. Just the facts, ma'am: coming clean about fertility. Fertil Steril 2003;80 Suppl 4:27-9.

26. Hammarberg K, Clarke VE. Reasons for delaying childbearing: a survey of women aged over 35 years seeking assisted reproductive technology. Aust Fam Physician 2005;34:187-8.

27. Galbally R, Fidler A, Chowdhury M, Tang KC, Good S, Tantivess S. Ten-year review of Thai health promotion foundation: Nov 2001Nov 2011. Bangkok: Thai Health Promotion Foundation; 2011.

28. Fordham G. Whisky, women and song: men, alcohol and AIDS in northern Thailand. Aust J Anthropol 1995;6:154-77.

29. Chan KY, Stoove MA, Sringernyuang L, Reidpath DD. Stigmatization of AIDS patients: disentangling Thai nursing students' attitudes towards HIV/AIDS, drug use, and commercial sex. AIDS Behav 2008;12:146-57.

30. Castaldelli-Maia JM, Ventriglio A, Bhugra D. Tobacco smoking: from 'glamour' to 'stigma'. A comprehensive review. Psychiatry Clin Neurosci 2016;70:24-33.

31. Pawloski LR, Ruchiwit M, Markham SM. The growing burden of obesity in Thailand: a review of current trends and policies. Pediatr Nurs 2011;37:256-61.

32. Ministry of Education of Thailand. A report of sexuality education in Thai academic institutes [Internet]. New York: UNICEF; 2016 [cited 2018 Feb 27]. Available from: https://www.unicef. org/thailand/tha/CSE_TH_070217(web).pdf.

33. Kay NS, Jones MR, Jantaraweragul S. Teaching sex education in Thailand. J Res 2010;5:10-6.

34. Pipat KP. Gender and sexual discrimination in popular Thai Buddhism. J Faith Spiritual Soc Change 2007;1:68-82.

35. Bureau of Reproductive Health [Internet]. Mueang Nonthaburi: Ministry of Public Health; 2018 [cited 2018 Feb 27]. Available from: http://203.157.68.27/result.php?q=subcat\&catid=4\&subid=1.

36. Population of 2017. Population of Bangkok 2017 [Internet]. Population of 2017; 2017 [cited 2018 Feb 27]. Available from: http:// populationof2017.com/population-of-bangkok-2017.html. 